\title{
IT-based support applications for patient patronage after hip joint arthroplasty (preliminary report)
}

\author{
O.A. Kaplunov ${ }^{1}$, Yu.A. Orlova ${ }^{2}$, A.V. Zubkov² ${ }^{2}$ E.Yu. Nekrasovi ${ }^{1}$, R.I. Gabidullin ${ }^{1}$, \\ V.M. Konstantinov' ${ }^{2}$, V.L. Rosaliev², K.O. Kaplunov ${ }^{1}$ \\ ${ }^{1}$ Volgograd State Medical University, Volgograd, Russian Federation \\ ${ }^{2}$ Volgograd State Technical University, Volgograd, Russian Federation
}

\begin{abstract}
Introduction The article considers the situation with modern user's applications for patients in the post-operative period after surgical interventions, including total hip replacement. The main reasons for the emergence of a multidisciplinary field of a science, in particular between the medical and IT industries, were formulated. The aim of the study was to develop a technology for preventive analysis, control and management of patient actions at the stage of outpatient medical rehabilitation by developing and implementing a universal software platform of an application and a chatbot on a mobile device and PC. Material and methods The study presents a universal software platform on a mobile device and a PC, in which the doctor introduces personalized indications based on existing clinical recommendations that permit to target the patient's behavior in an expert-based vector of preventive measures. The paper presents the database scheme, usage scenarios, interface, and an example of a recommendation for a random patronage day. Results The comparative results in the aspect of complications in the patients who used the software product after discharge from the hospital with those in the patients without software patronage were analysed. The overall percentage of complications and of each specific one among them was significantly more frequent in the comparison group than in the observation group with IT-based support $(\mathrm{p}<0.001)$. Patient satisfaction with the app was studied based on an anonymous survey, and a high satisfaction rate was revealed. Discussion The introduction of the software product into clinical work in comparison with existing analogues provided better patients' compliance, especially in older persons with cognitive comorbidity, to targeted behavioral information, prevention of non-compliance with the medication dosage regimen and mobile activity, thus improving the long-term treatment results in patients at the stage of the rehabilitation. Conclusion It has been concluded that the results of the study indicate the feasibility and clinical validity of the development and implementation of the application developed and of similar software products.
\end{abstract}

Keywords: information system, mobile application, chat bot, hip replacement, post-operative period

\section{INTRODUCTION}

The demographic processes in the recent decades, characterized by a growing shortage of labor resources and the growing demands of the social mentality in the field of ensuring a decent quality of life, dictate the need for effective and accelerated medical and social rehabilitation of patients suffering from chronic somatic diseases (diabetes mellitus, orphan diseases, etc.) and of those who have undergone surgical treatment, in particular, joint replacement.

Total hip arthroplasty (THA) remains one of the most frequent and widespread types of arthroplastic interventions in the recent decades in which degenerative articular surfaces are replaced with implants [1]. However, it is necessary to fulfill a number of conditions ensureing correct and long-term performance of the implanted components, one of which is an accurate execution of the recommendations prescribed by the attending surgeon. If the permitted mode of physical activity is not observed, the patient can develop a severe complication, dislocation of the hip joint endoprosthesis. To reduce it, revision is a need in $45-57 \%$ of cases [2]. It increases the risks of treatment and can lead to a negative outcome. No less significant is the meticulous implementation of measures for prevention of thromboembolic complications, primarily a long-term and regular intake of anticoagulant drugs. The compliance of elderly people, who are the main THA contingent, to this measure is low, and the omission in taking medications a serious threat for their health and life $[3,4]$.

In this regard, and in the light of the recent events related to the organization of quarantine measures and the difficulties of personal contact between the patient and the attending physician, it is obvious that there is a need to provide patients with remote medical patronage and open access to informed and individualized management of treatment measures at the outpatient stage. Meanwhile, the creation of such platforms is possible, first of all, due to the joint efforts of doctors of various profiles and specialists in the field of programming. The analysis of literature data demonstrates the presence of applied software products focused on the format of telemedicine. These products allow a patient to carry out a real-time consultation with a doctor on a specific issue, 
but do not provide an opportunity to personally build a rehabilitation plan $[5,6]$.

The creation of an easily feasible opportunity to access both individual recommendations and offline contact with the attending physician is the basis and principle of the proposed software platform.

The aim of the study was to develop a technology for preventive analysis, control and management of the patient's actions after THA for medical rehabilitation at the stage of outpatient treatment by creating and implementing a universal software platform for a mobile device and PC as an application and a chatbot.

To solve this goal, it was necessary to solve the following tasks:

- to analyze the approaches to monitoring and managing the treatment and rehabilitation process in patients at the outpatient treatment stage, systems of monitoring and management of the treatment and rehabilitation process, to identify their advantages and disadvantages;

- to develop a database based on clinical guidelines for monitoring and managing the treatment and rehabilitation process at the stage of outpatient treatment;

- to design and implement software for remote medical patronage of patients at the stage of outpatient treatment using the THA intervention (doctor's interface for a PC and a mobile device for patients);

- to carry out a comparative analysis of the objective (the number of complications and consultations of the patient after discharge from the hospital) and subjective (survey of patients' satisfaction with the software product and patronage) impact of the application implementation in practice.

\section{MATERIAL AND TECHNOLOGY}

To achieve the goals, a software platform has been generated, which, based on existing clinical recommendations, enables to upload doctor's personalized prescriptions that allow to purposefully manage patient's behavior in an expert-based vector of preventive measures to achieve a better clinical result and reduce the number of possible, primary, and significant complications. At the same time, the platform format is focused on the interaction between the patient and the attending physician in real time to assess and control the behavioral steps taken by the patient.

For correct operation of the software product, a database has been developed based on clinical guidelines. On its basis, the application provides monitoring and management of the treatment and rehabilitation process of patients at the outpatient stage, including daily recommendations for a patient for 35 days after the operation (Table 1).

In addition, for partial use of these developments, patients who own mobile devices on the iOS platform, can use a chatbot. It should be noted that intellectual property documents have been received for the software platform, database and chatbot ${ }^{1}$. Installation and training of the patient (or his/her relatives) to use the application was conducted by the attending physician in the postoperative period of the inpatient stage.

Table 1

Example of recommendations on the second post-operative day

\begin{tabular}{|c|c|c|c|}
\hline \multicolumn{4}{|l|}{ Day 2} \\
\hline \multicolumn{4}{|c|}{ Recommendation } \\
\hline \multicolumn{4}{|c|}{$\begin{array}{l}\text { Contents } \\
\text { It is necessary to walk using a walker for support (for example, walk independently } 20-30 \mathrm{~m} \text { along the corridor). } \\
\text { Remember to reduce the amount of flexion in the operated joint. Perform breathing exercises. } \\
\text { Continue using compression items. It is necessary to prevent thromboembolic complications. } \\
\text { From today on, you will be taking iron supplements to elevate the hemoglobin lost during the operation.. }\end{array}$} \\
\hline \multicolumn{4}{|c|}{$\begin{array}{l}\text { Important: } \\
\text { Do not take off your stockings. Do not forget about the range of motion in the joint permitted. }\end{array}$} \\
\hline \multicolumn{4}{|c|}{$\begin{array}{l}\text { Message: } \\
\text { See next recommendation! }\end{array}$} \\
\hline \multicolumn{4}{|c|}{ Drugs } \\
\hline Name & Dose & Administration & Time of intake \\
\hline Fraxiparin & $\begin{array}{l}0.3 \mathrm{ml} \text { subcutaneously }(0.4 \mathrm{ml} \mathrm{in} \\
\text { body weight of more than } 70 \mathrm{~kg}\end{array}$ & Percutaneous injection & $\begin{array}{l}\text { As indicated by an } \\
\text { attending doctor }\end{array}$ \\
\hline Sorbifer & 1 pill $x 1$ time a day & Pill (per os) & $12: 00$ \\
\hline
\end{tabular}

Orlova Yu.A., Kaplunov O.A., Nekrasov E.Yu. et al. B2Doc-Endoprosthetics. Certificate of state registration of a computer program No. 2019615075. 2019. Bull. No. 4.

Orlova Yu.A., Kaplunov O.A., Nekrasov E.Yu. et al. B2Doc-Chatbot. Certificate of state registration of a computer program No. 2019618560.2019. Bull. No. 4.

Orlova Yu.A., Kaplunov O.A., Nekrasov E.Yu. et al. B2Doc-Endoprosthetics. Certificate of state registration of the database No. 2019620628.2019.

Bull. No. 4. 
To assess the effects of the developed software product on the course and results of the rehabilitation process, we studied complications in the period of 1.5 months after the surgical intervention with apps support. And namely, the number of clinically significant deep vein thrombosis (DVT) if Xarelto 10 mg was taken as an anticoagulant drug, hip dislocation in the endoprosthesis, and patient opinion expressed in an anonymous survey. In addition, within the framework of the study, we analyzed the number of patients of both groups seeking counseling and other assistance at the outpatient treatment stage based on the analysis of outpatient observation charts.
For this purpose, we selected two groups of patients who underwent the surgical intervention in 2018 or 2019 at the orthopaedic centre of the Federal State Budgetary Healthcare Institution "VMKTs" of the FMBA of Russia. The main (observation group) consisted of 24 people who were enrolled prospectively by the method of continuous sampling. The comparison group of 82 patients was formed retrospectively according to the same principle of inclusion. This group was a sample of patients who had been operated in the previous year of work. As a result, the study included 106 subjects among which women with idiopathic coxarthrosis over the age of 55 years prevailed (Table 2).

Table 2

Clinical characteristics of patients $(n=106)$

\begin{tabular}{|l|c|c|c|c|c|c|c|c|}
\hline \multirow{2}{*}{ Etiology } & \multicolumn{3}{|c|}{ Sex } & \multicolumn{3}{c|}{ Age } & Comparison & Observation \\
group & Troup & Total, $\mathrm{n}(\%)$ \\
\cline { 2 - 6 } & $\mathrm{M}$ & $\mathrm{F}$ & $45-55$ & $56-65$ & $66+$ & 48 & 12 & $60(56.6)$ \\
\hline Idiopathic & 23 & 37 & 3 & 24 & 33 & 12 & 6 & $17(16)$ \\
\hline Avascular & 13 & 4 & 12 & 4 & 1 & 11 & 1 & $4(3.7)$ \\
\hline Post-traumatic & 3 & 1 & 2 & 1 & 1 & 3 & 5 & $25(23.7)$ \\
\hline Dysplastic & 10 & 15 & 2 & 13 & 10 & 20 & 24 & $106(100)$ \\
\hline Total: & 49 & 57 & 19 & 42 & 45 & 82 & \\
\hline
\end{tabular}

\section{RESULTS}

The installation of the application on mobile platforms with recommendations after hip arthroplasty provided timely regular information to the patient about the necessary actions and behavior at various stages of rehabilitation after surgery, as well as familiarization with the reference information on surgical treatment prescribed to the patient by his/her attending physician. Another significant advantage is reduction in the frequency of unscheduled visits to the clinic for consultation with the attending physician.

The general operating principle of the designed application is presented in the diagram of the scenarios of its use (Fig. 1). The diagram includes the subjects presented by the following users: Administrator, Attending physician (hereinafter - Doctor), Patient.

For any actions in the system, the user is authorized with his own phone number and password. After logging into the system, the user Patient sees a warning, an example of which is in Appendix 1 to this document, then is transferred to the page for viewing current recommendations. After authorization, the Doctor sees a screen with a list of his patients, and the Administrator - a list of doctors and patients registered in the system.

The User Patient performs viewing daily recommendations in the postoperative period, the reference book, and can also edit some information of his account (change the password, update the phone number). The patient does not have access to change the type of surgery, its date and personal recommendations.

The User Doctor can view a list of his/her patients, edit their data (including data on the type of surgery, its date and personal recommendations for a particular patient).

The user Administrator user has access to most functions of the service: he can register the Doctor and the Patient, view the lists of registered users, change any of their data. The Administrator also has the ability to add content (information about surgical treatment, recommendations) to the database.

Application screen forms are shown in Figure 2.

As a result of the analysis of the complications indicated above, it was found that in the comparison group at the stage of outpatient rehabilitation, one patient developed thromboembolism of large branches of the pulmonary vascular tree, which, despite the provision of medical and resuscitation measures to her, led to a fatal outcome. Two other patients had edema of the lower leg and foot of the operated limb that appeared from the $3 \mathrm{rd}$ week of the postoperative period and persisted for a long time. It was regarded as a manifestation of DVT in the lower leg veins or the lower third of the thigh (USDG was not performed due to organizational and social reasons). 
Genij Ortopedii, Vol. 26, no 4, 2020

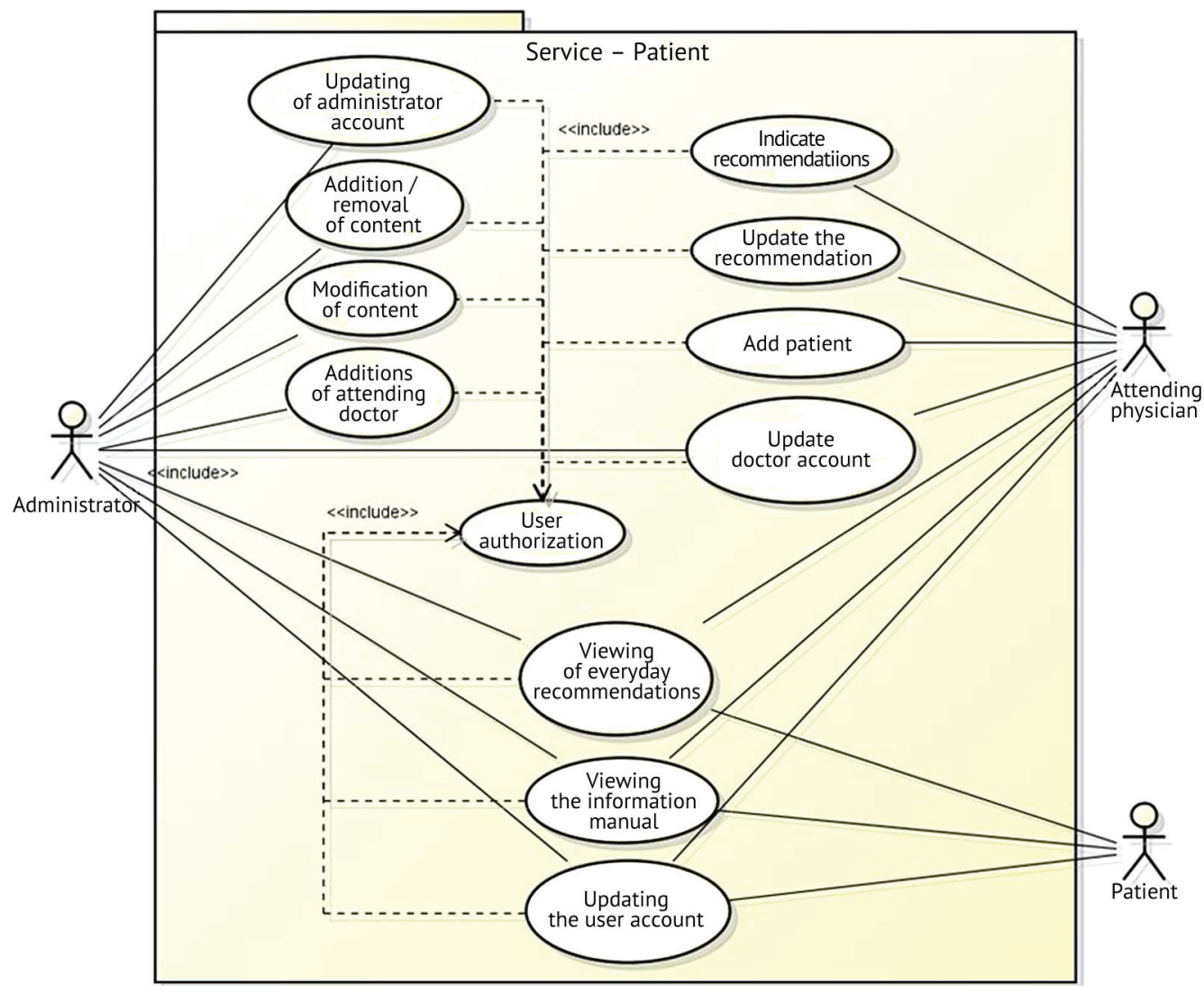

Fig. 1 Diagram of scenarios for using the software product
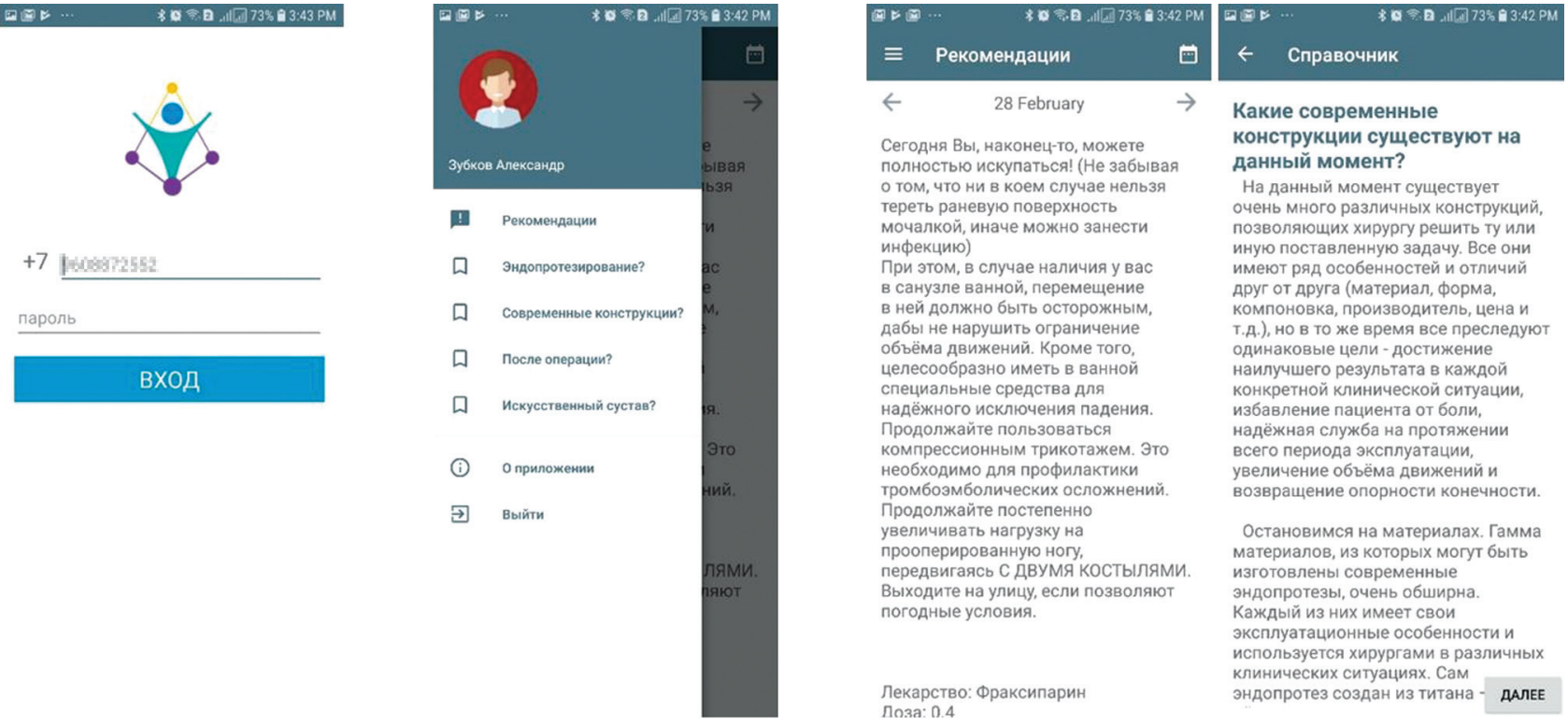

Fig. 2 Application interface for the patient with recommendations and a guide

In addition, one of the patients in this group had a single dislocation of the hip resulting from violation of the motor regime in the 4 th week after the operation. He sat in the driver's seat of a low Sedan and luxation occurred when he was leaving the car (recommendations of the B2Doc-Endoprosthetics allow such activity only 2-2.5 months after surgery). Thus, the overall complication rate was $4.9 \%$; vascular incidents (including fatal thromboembolism of the lung artery) occurred in $3.65 \%$ of cases and hip dislocation in $1.22 \%$ (Table 3 ).
Table 3

Features and number of the complications encountered $(n=106)$

\begin{tabular}{|l|c|c|c|}
\hline $\begin{array}{c}\text { Complication } \\
\text { type }\end{array}$ & $\begin{array}{c}\text { Observation } \\
\text { group, } \mathrm{n}(\%)\end{array}$ & $\begin{array}{c}\text { Comparison } \\
\text { group, } \mathrm{n}(\%)\end{array}$ & $\begin{array}{c}\text { Total, } \mathrm{n} \\
(\%)\end{array}$ \\
\hline DVT & $1(4.1)$ & $2(2.43)$ & $3(2.8)$ \\
\hline TELA & - & $1(1.22)$ & $1(0.94)$ \\
\hline $\begin{array}{l}\text { Femur } \\
\text { dislocation }\end{array}$ & - & $1(1.22)$ & $1(0.94)$ \\
\hline Total & $1(4.1)$ & $4(4.9)$ & $5(4.7)$ \\
\hline
\end{tabular}


In the main group, the quality and quantity of complications were different. Thus, there were no dislocations in patients of this group during the observation period. One patient, who had concomitant pathology of type 2 diabetes mellitus, developed non-occlusive thrombosis of the sural veins of the unoperated limb on the 23rd day (confirmed by ultrasound, clinically manifested by edema of the leg and foot). Thus, in the main group, the complications in qualitative and quantitative terms were somewhat less significant from a clinical point of view.

The study of the data of an anonymous survey of satisfaction with the use of the proposed application in all participants of the main group showed the predominance of positive ratings (satisfied, rather satisfied - 22 respondents or $84.6 \%$ ). Only two patients were not included in this evaluation category, and one of them due to difficulty with the exact formulation (Fig. 3)

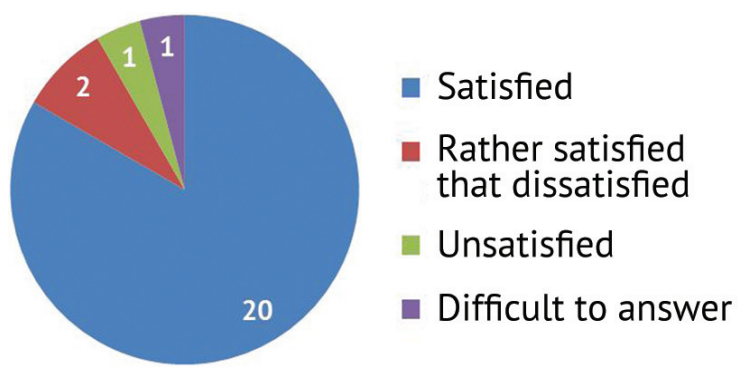

Fig. 3 Satisfaction of patients of the main group with the use of software patronage

Comparative analysis of outpatient visits of patients in both groups showed that with a relatively equal number of appointments on medical issues (dressings, removal of stitches, etc.), the number of requests for advice to clarify the motor and behavioral regimen and drug intake in the comparison group was significantly higher. So, from the main group, only one patient applied for consultation (4.1\%), while from the comparison group there were 12 visits (14.6\%).

\section{DISCUSSION}

As a result of the study, the available and universal tools for monitoring and management of the treatment and rehabilitation process in THA patients after discharge from the hospital were analysed. IT-based technologies for online monitoring and management of the rehabilitation process in the outpatient conditions have been poorly represented on the market of soft products, which, among other reasons, determines a fairly high percentage of complications of treatment measures [7]. At the moment, several online services have been known.

These are, for example, "Doc + Online", "Yandex Health", "Doctor near online", "Doctor in touch", "Doctor near". Their main task is to work in the "question-answer" mode in real time for a specific situation [8]. At the same time, they do not provide an opportunity to individually build a rehabilitation scheme and are not based on clinical recommendations in certain medical specialties, what has been stressed in the latest regulations of the government of the Russian Federation [9]. In order for a patient to receive an answer to a question of interest, it often takes a considerable period of time. Moreover, the doctor must constantly have access to the patient's medical records, which significantly complicates the operation of these services and calls into question its effectiveness and expediency.

The creation on the basis of a universal software platform of an original application for patients after total arthroplasty, the content of which is based on the standards and clinical recommendations of the expert community, enablkes to avoid the indicated disadvantages of the analogue developments and, due to specific online recommendations and an intuitive interface, positively influence to avoid complications which might be caused due to discredited patient behavior. The introduction of the software product into clinical work has ensured a high adherence of patients, especially older persons with cognitive concomitant impairments, to the implementation of the recommendations received on the motor and behavioral regimen, to practically eliminate noncompliance with medication and thereby improve the immediate and long-term results of treatment.

Undoubtedly, the analysis performed in a relatively small study group does not allow for the time being to draw statistically substantiated conclusions about a significant decrease in the number of complications at the outpatient stage. Nevertheless, the anonymous survey undoubtedly shows high patient satisfaction with the use of the mobile application and their better adherence to perform recommendations. It is also confirmed by a comparative analysis of the number of visits by patients of both groups at the outpatient stage to receive consultative assistance. High percentage of patients in the comparison group who sought consultation, on the one hand, indicates their lack of knowledge after discharge, on the other hand, demonstrates the additional costs of the healthcare system to eliminate such shortcomings.

The results obtained clearly demonstrate that the development and implementation of innovative measures in this direction will increase the efficiency 
and shorten the time of medical and social rehabilitation, thereby ensuring the speedy recovery of the quality of life indicators and social rehabilitation of patients. It will help reduce the state budget expenditures on benefits for temporary and permanent disability [10]. The expediency of further research in this direction is obvious, including with the involvement of grants at various levels.

\section{CONCLUSION}

This preliminary study proposes a software product, an application for mobile platforms. Its advantages and disadvantages were revealed, a database was developed based on clinical recommendations for monitoring and managing the treatment and rehabilitation process of patients at the outpatient treatment stage. It enabled to design and to

use a software system for remote medical patronage of patients at the outpatient treatment stage after joint replacement surgery (doctor's interface for a PC and on patient's mobile device). The introduction of the proposed one and further developed similar innovations into practice will improve the outcomes of hip and other large joints replacement.

This work was partially supported by the Russian Foundation for Basic Research (grant 18-07-00220).

\section{REFERENCES}

1. Malek I.A., Royce G., Bhatti S.U., Whittaker J.P., Phillips S.P., Wilson I.R., Wootton J.R., Starks I. A comparison between the direct anterior and posterior approaches for total hip arthroplasty: the role of an 'Enhanced Recovery' pathway. Bone Joint J., 2016, vol. 98-B, no. 6, pp. 754-760. DOI: 10.1302/0301-620X.98B6.36608

2. Abdulnasyrov R.K., Kireev S.I., Voskresenskii O.Iu., Markov D.A., Letov A.S., Iusupov K.S., Frolenkov A.V., Nam A.V., Pavlenko N.N. Revizionnoe endoprotezirovanie tazobedrennogo sustava po povodu vyvikha golovki u bolnykh s displasticheskim koksartrozom [Revision hip arthroplasty for the head dislocation in patients with dysplastic coxarthrosis]. Sovremennye Problemy Nauki i Obrazovaniia, 2015, no. 6. (in Russian) Available at: https://science-education.ru/ru/article/view?id=23435

3. Morozova T.E., Minnigulov R.M., Iudina I.Iu., Lychagin A.V. Analiz mezhlekarstvennykh vzaimodeistvii u patsientov posle endoprotezirovaniia krupnykh sustavov nizhnikh konechnostei [The analysis of drug-drug interactions in patients after arthroplasty of the lower limb large joints]. Vestnik Smolenskoi Gosudarstvennoi Meditsinskoi Akademii, 2018, vol. 17, no. 1, pp. 112-119. (in Russian)

4. Kaplunov O.A., Biriukov S.N. K voprosu sovershenstvovaniia endoprotezirovaniia tazobedrennogo sustava v aspekte snizheniia krovopoteri [On the problem of improving hip arthroplasty in terms of reducing blood loss]. Materialy XI Vseros. Sezda travmatologov-ortopedov "Dostizheniia Rossiiskoi Travmatologii i Ortopedii". In 3 volumes [Proceedings of XI Congress of traumatologists-orthopaedists "Progress in Russian Traumatology and Orthopaedics"]. Spb., 2018, vol. 1, pp. 146-149. (in Russian)

5. Konstantinov V.M., Rosaliev V.L., Orlova Y.A., Zaboleeva-Zotova A.V. Development of the 3D Human Body Model. In: Abraham A., Kovalev S., Tarasov V., Snášel V. (eds.) Proceedings of the First International Scientific Conference "Intelligent Information Technologies for Industry" (IITI'16). Series: Advances in Intelligent Systems and Computing. Vol. 451. Springer, Cham, 2016, pp. 143-152. DOI: 10.1007/978-3-319-33816-3_15

6. Rozaliev V.L., Vybornyi A.I., Orlova Y.A., Alekseev A.V. Methods and applications for controlling the correctness of physical exercises performance. In: IV International Conference on Information Technology and Nanotechnology. 2018, P. 344-351. DOI: 10.18287/1613-0073-2018-2210-344-351

7. Koneva E.C., Serebriakov A.B., Shapovalenko T.V., Liadov K.V. Analiz 5-letnego opyta raboty multidistsiplinarnoi brigady po protokolu fast-trackterapii posle operatsii totalnogo endoprotezirovaniia tazobedrennykh i kolennykh sustavov v klinike FGAU «Lechebno-reabilitatsionnyi Tsentr» Minzdrava Rossii [The analysis of 5-year work experience of a multidisciplinary team under the fast-track-therapy protocol after total hip and knee arthroplasty surgeries in FSAI "Treatment-and-rehabilitation Centre" Clinic of the RF Ministry of Health]. Fizioterapiia, Balneologiia $i$ Reabilitatsiia, 2016, vol. 15, no. 4, pp. 175-182. (in Russian)

8. Bahadori S., Wainwright T.W., Ahmed O.H. Smartphone apps for total hip replacement and total knee replacement surgery patients: a systematic review. Disabil. Rehabil., 2020, vol. 42, no. 7, pp. 983-988. DOI: 10.1080/09638288.2018.1514661

9. Khodorovich P.V. Razrabotka multiplatformennogo prilozheniia dlia virtualnykh meditsinskikh konsultatsii [Development of a multi-platform application for virtual medical consultations]. Zhurnal Telemeditsiny i Elektronnogo Zdravookhraneniia, 2016, no. 1 (2), pp. 18-23. (in Russian)

10. Vesterby M.S., Pedersen P.U., Laursen M., Mikkelsen S., Larsen J., Søballe K., Jørgensen L.B. Telemedicine support shortens length of stay after fast-track hip replacement: A randomized controlled trial. Acta Orthop., 2017, vol. 88, no. 1, pp. 41-47. DOI: 10.1080/17453674.2016.1256939

Received: 08.05.2020

\section{Information about the authors:}

1. Oleg A. Kaplunov, M.D., Ph.D., Professor,

Volgograd state medical University, Volgograd, Russian Federation, Volgograd medical clinical center of the Federal medical and biological Agency of the Russian Federation, Volgograd, Russian Federation, Email: volortho@mail.ru

2. Julia A. Orlova, Ph.D. of Engineering Sciences, associate Professor, Volgograd state technical University, Volgograd, Russian Federation, Email: ylia.orlova@gmail.com

3. Alexander V. Zubkov,

Volgograd state technical University, Volgograd, Russian Federation, Email: zubkov.alexander.v@gmail.com

4. Evgeniy Yu. Nekrasov, M.D.,

Volgograd state medical University, Volgograd, Russian Federation, Volgograd medical clinical center of the Federal medical and biological Agency of the Russian Federation, Volgograd, Russian Federation, Email: freagrence@yandex.ru
5. Rustam I. Gabidullin, M.D.

Volgograd state medical University, Volgograd, Russian Federation, Volgograd medical clinical center of the Federal medical and biological Agency of the Russian Federation, Volgograd, Russian Federation, Email: ftgs-silver7@mail.ru

6. V. M. Konstantinov,

Volgograd state medical University, Volgograd, Russian Federation

7. V. L. Rosaliev,

Volgograd state medical University, Volgograd, Russian Federation

8. Kirill O. Kaplunov, M.D., Ph.D., associate Professor,

Volgograd state medical University, Volgograd, Russian Federation,

Email: kkaplunovtmss@yandex.ru 